\title{
http://bjas.journals.ekb.eg \\ Evaluation of Peripapillary Retinal Nerve Fiber Layer Thickness before and after Phacoemulsification
}

Y.F.Abdo , A.A.Fayed,T.N.Attiya and E.H.El-mahdy

Ophthalmology Dept., Faculty of Medicine, Benha Univ., Benha, Egypt

E-Mail: E.Hamdy@gmail.com

\begin{abstract}
phacoemulsification continues to be one of the most popular surgical procedures for cataract extraction in the ophthalmologic practice. Macular edema is one of the most common complications of cataract surgery, It is the main cause of the postoperative visual impairment and its incidence is $0.1-9 \%$. To detect the changes in prepapillary retinal nerve fiber layer and macular thickness after phacoemulsification surgery by the OCT. 30 eyes of 30 patients who underwent uncomplicated phacoemulsification between sept. 2018 and feb. 2019 at the ophthalmology department at Benha university hospital were included in the study, Spectral domain optical Coherence Tomographywas done before phacoemulsification then one week and one month after the surgery for Macular examination and Retinal nerve fiber layer examination. patients age range between (45-65) years old. the average retinal nerve fiber layer thickness after one week and one month of the surgery were significantly higher than those measured preoperatively $(\mathrm{P}<0.001)$. there was a statistically significant increase in the central macular thickness in the 1st week and the 1st month after surgery than before it $(\mathrm{P}<0.001)$. phacoemulsification can cause a significant increase in the RNFL and central macular layer thickness in the 1 st week \& the 1st month after the surgery than before it.
\end{abstract}

Keywords: Phacoemulsification, Retinal nerve, Peripapillary.

\section{Introduction}

Phacoemulsification is a modern cataract surgery in which the eye's internal lens is emulsified with an ultrasonic hand piece and aspirated from the eye. The basic phacoemulsification hand piece and tip use a longitudinal US power that acts in a back-andforth motion aligned with the longitudinal axis of the phacoemulsification tip. This results in cutting the lens material as the tip impacts the lens and cause chattering and repulsion of the lens fragments away from the aspirating port [1].

Various factors involved in phaco can influence the tissue structures of the eyeball. The ultrasonic energy can produce mechanical effects that cause an inflammatory reaction, compression, and hypoxia of the tissue. due to instantaneous pressure fluctuation [2]. The ultrasonic energy that was emitted could be controlled through the estimation of the phaco time [3].

The retina is the sensory tissue that requires more oxygen than the brain; so it is highly sensitive to changes in oxygen levels [4]. The macula is an important structure which is responsible for the 30degree field of view, which greatly determines the quality of sharp vision, communication, interpersonal relationships, color vision and contrast sensitivity [5].

The retinal nerve fiber layer (RNFL) has been of great interest to the peripheral visual field (6). Cystoid macular edema (CME) is characterized by accumulation of fluid in the extracellular spaces of the retina due to impairment in the blood-retinal barrier that leads to formation of cystoid structures in the external plexiform and inner nuclear layers of the retina [7].

Nonsteroidal anti-inflammatory drugs (NSAIDs) inhibit the prostaglandin biosynthesis so prevent the macular edema after phacoemulsification [8]. Optical coherence tomography (OCT) is a new technology that permits a high-resolution cross-sectional image of the biological tissues using light. OCT can image detailed ocular structures in a simple, fast and non-invasive technique [9].

\section{Aim of the work}

Aim of the study is to evaluate the changes in peripapillary retinal nerve fiber layer (RNFL) and central macular thickness before and after phacoemulsification using Ocular Coherence Tomography.

\section{Subject and method}

The present study is a selective prospective study that included 30 eyes of 30 patients who underwent cataract surgery (phacoemulsification) between september 2018 and february 2019 at the ophthalmology department of Benha university hospital.

\subsection{The inclusion criteria}

Each pateint had underwent full ophthalmological examination with the following criteria: VA and best corrected visual acuity; Normal anterior chamber; An open angle on slitlamp examinations; Suitable lens opacities not interfers with biometry and SD-OCT 
examinations; Intraocular pressure (IOP) $<21$ $\mathrm{mmHg}$.

\subsection{The exclusion criteria}

Patients with any retinal diseases as senile macular degeneration, macular hole, vascular diseases, epiretinal membranes or other ocular diseases like glaucoma, uveitis, amblyopia, previous history of intraocular surgery and laser treatment were excluded ; Patients who were on topical or systemic steroid or diuretics that may affect retinal thickness were excluded and Patients who had systemic diseases like diabetes and hypertension were excluded.

\subsection{All patients had the following examination \\ -Visual acuity and best corrected visual acuity. \\ - Slit lamp examination:}

i. The anterior segment was carefully examined by the slit lamp for detection of any abnormalities, checking the depth of the anterior chamber, examination of the iris , pupil for reaction and reactivity and lens examination to detect the type of cataract and lens position to exclude subluxation, dislocation and any congenital anomalies.

ii. IOP measurement by Goldman applanation tonometry

iii. The posterior segment examination.

iv. OCT measurements: Spectral domain optical coherence tomography, Topcon 3D OCT 2000 software (version 4.1) instrument is used to measure the peripapillary RNFL and the central macular thickness before the phacoemulsification, then after one week and one month.Three scans were obtained for each tested eye and the mean of these scans was used for the analysis.

Spectral domain optical Coherence Tomography was done before phacoemulsification then one week and one month after the surgery.

Macular examination: The patients was asked to fix on an internal target and the operator centered the macular scans on the foveal pit, we selected the retinal map analysis protocol on the OCT to reconstruct a surface map as a false-color topographic image displayed with the numeric averages of the measurements.

Retinal nerve fiber layer examination: the OCT software calculated the average RNFL thickness.

\subsection{The surgical Procedure}

All surgeries were performed in the ophthalmology department of Benha university using the phaco machine under an operating microscope (Megatron S4-1248430-G type).

\section{I-Preoperative preparation}

Prior to the surgery, $1 \%$ tropicamide, $1 \%$ cyclopentolate, $\quad 2.5 \% \quad$ phenylephrine hydrochloride was dropped into the eyes of all patients for 4 times at 10-min intervals.

\section{II- Anesthetic Technique}

Peribulber injection of lidocaine (Xylocaine) was used to provide anesthesia and akinesia during surgery.

\section{III- Surgical technique}

Standard steps of phacoemulsification procedure were done including corneal incision. Capsulorhexis , Hydrodissection ,Bimanual phacoemulsification, Irrigation/aspiration of the residual cortex. , Intracapsular IOL implantation then In the postoperative period, the patients used $0.3 \%$ ofloxacin at a daily dose of $5 \times 1$ drop for 7 days ,Steroid eye drop as prednisolone acetate $1 \%$ at daily dose as 5time/day for 7 days Patients who developed intraoperative or postoperative complications were excluded from the study.

The study was carried out in the accordance with the ethical standards stated in the declaration of Helsinki and was approved by the Ethical Committee of Benha Medical School.

\subsection{Statistical analysis}

The clinical data were recorded on a report form. These data were tabulated and analyzed using the computer program SPSS (Statistical package for social science) version 20 to obtain: Descriptive statistics were calculated for the data in the form of: Mean and standard deviation $( \pm \mathrm{SD})$.Median and inter-quartile range (IQR) for quantitative data. Frequency and distribution for qualitative data. In the statistical comparison between the different groups, the significance of difference was tested using one of the following tests:- Paired $t$ test and willcoxon test: Used to compare mean of variables in different time periods of quantitative data of parametric and nonparametric variables respectively.

\section{Results}

Thirty eyes of 30 patients, 12 males and 18 females, were included in this study, All pateints underwent phacoemulsification surgery in the ophthalmology department of Benha university hospital. Their mean age was $58.3 \pm 7.46$ years, The demographic data and distribution of the study group in Table (1) 
Table (1) Distribution of the studied group (30 patients).

\begin{tabular}{|c|c|c|c|c|}
\hline & mean \pm SD & Min & Max & Median (IQR) \\
\hline Age & $58.3 \pm 7.46$ & 40 & 67 & $58(57-65)$ \\
\hline Sex $n(\%)$ & & & & \\
\hline Male & $12(40.0) \%$ & & & \\
\hline Female & $18(60.0) \%$ & & & \\
\hline \multicolumn{5}{|l|}{ Preoperative Visual Acuity n (\%) } \\
\hline $1 / 60$ & $3(10.0) \%$ & & & \\
\hline $2 / 60$ & $3(10.0) \%$ & & & \\
\hline $3 / 60$ & $3(10.0) \%$ & & & \\
\hline $6 / 36$ & $9(30.0) \%$ & & & \\
\hline $6 / 60$ & $12(40.0) \%$ & & & \\
\hline Preoperative Best Corrected & & & & \\
\hline Visual Acuity n (\%) & $12(40.0) \%$ & & & \\
\hline $6 / 24$ & $9(30.0) \%$ & & & \\
\hline $6 / 36$ & $9(30.0) \%$ & & & \\
\hline $6 / 60$ & & & & \\
\hline $\begin{array}{l}\text { Pre operative Central Macular } \\
\text { Thickness }\end{array}$ & $229.9 \pm 35.02$ & 164 & 304 & $226.5(217234)$ \\
\hline $\begin{array}{l}\text { Pre-operative Retinal Nerve Fiber } \\
\text { layer thickness }\end{array}$ & $83.1 \pm 12.36$ & 64 & 99 & $85(74-95)$ \\
\hline $\begin{array}{l}\text { Central Macular Thickness } 1 \mathrm{w} \\
\text { post operative }\end{array}$ & $257.8 \pm 25.15$ & 232 & 311 & $246.5(238274)$ \\
\hline $\begin{array}{l}\text { Retinal Nerve Fiber layer } \\
\text { thickness 1w postoperative }\end{array}$ & $113.1 \pm 56.96$ & 75 & 278 & $98.5(90-105)$ \\
\hline $\begin{array}{l}\text { Central Macular Thhickness } 1 \mathrm{~m} \\
\text { post operative }\end{array}$ & $284.7 \pm 24.44$ & 242 & 330 & $281.5(270296)$ \\
\hline $\begin{array}{l}\text { Retinal Nerve Fiber laayer } \\
\text { thicknss 1m postoperative }\end{array}$ & $107.8 \pm 21.56$ & 85 & 160 & $105(88-115)$ \\
\hline Intra ocular pressure & $16.31 \pm 1.39$ & 14.3 & 18.5 & $16.2(15.1-17.3)$ \\
\hline
\end{tabular}

The central macular and retinal nerve fiber thickness (CMT) before and after phacoemulsification were evaluated using OCT. The central retinal nerve fiber thickness(RNFLT) had significantly increased after one week of phacoemulsification $(\mathrm{p}<0.001)$ and also had significantly increased after one month

$(\mathrm{p}<0.001)$ Fig (1).

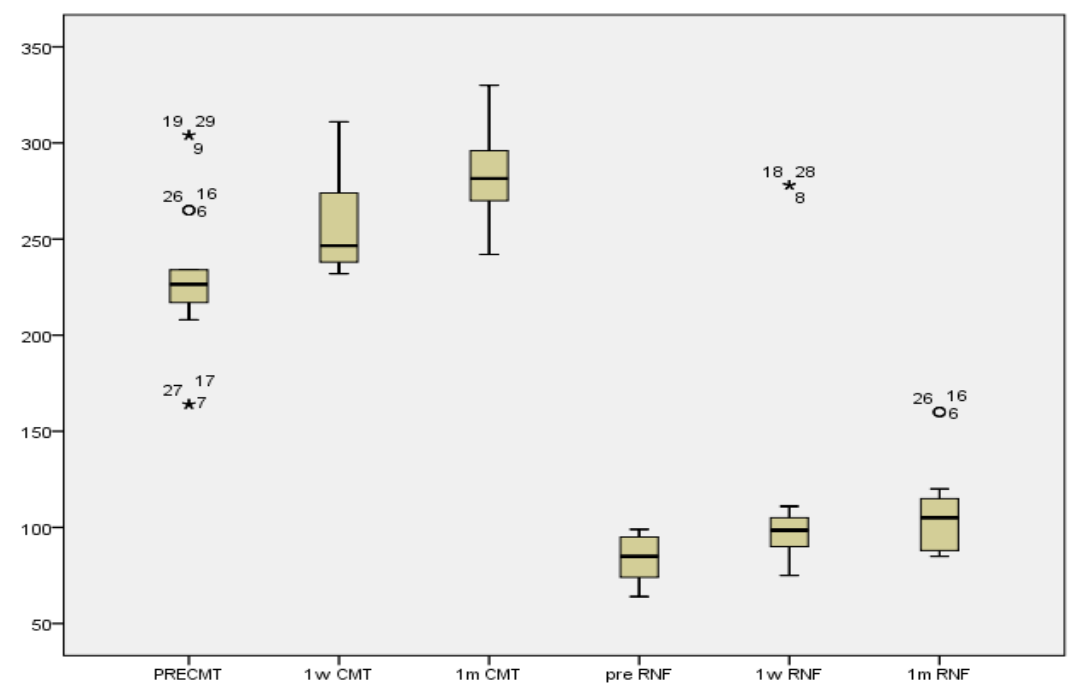

Fig (1) CMT and RNFLT in the preoperative follow up period, 1Week and 1Month postoperative shows increase in the CMT and RNFL T one month postoperative more than one week and more than preoperative period 


\section{Discussion}

In this study the central macular and retinal nerve fiber thickness before and after phacoemulsification were evaluated using OCT. The central retinal nerve fiber thickness had significantly increased after one week of phacoemulsification $(\mathrm{p}<0.001)$ and also had significantly increased after one month $(\mathrm{p}<0.001)$.

In agreement with our study; El-Ashry [10] detected that there was an increase in RNFL thickness measurements after phacomulsification, and according to the type of cataract he revealed that the cortical and posterior subcapsular cataracts significantly affected the OCT images more than the nuclear cataracts, this is due to that the nuclear cataracts cause minimal light scattering tham the cortical and posterior cataracts. Also Cheng in his study [11] agreed with our study and he found that after the removal of the cataract, thereis increase in RNFL thickness.

In this study, On examination of the Fovea there was a significant increase in the central macular thickness after one week $(\mathrm{P}<0.001)$ and also one month $(\mathrm{P}<0.001)$ after the operation and this is because the ultrasonic energy produce mechanical effect that leads to the release of phospholipids which in sequence release prostaglandins and other inflammatory mediators. These inflammatory mediators diffuse through the vitreous and disrupt the blood retinal barrier and cause macular.

In agreement with our study; Perente [12], compared the retinal thickness values before cataract surgery with the thickness at 1 day, 1 week, 1month, 3 month and 6 month after surgery, he found that the mean retinal thickness increased with every measurement. The greatest increase in retinal thickness was after 1 month from the surgery $(\mathrm{P}<0.05)$ followed by gradual decrease after 3 and 6 months from the surgery, after 6 month from the surgery, the macular thickness was still significantly greater than that was before the operation $(\mathrm{P}<0.05)$.

Also in agreement with our study: Yazici (13), has found a significant increase in the foveal thickness after the first week, 1 month and 3 months after the cataract surgery $(\mathrm{P}<$ $0.05)$; a nonsignificant difference in the foveal thickness was observed at 6 months after the operation. The greatest increase in the thickness of the entire macula was seen at 1 month after the surgery.

Gede Pardianto [14] had a study that matches with current study, it detected that on examination of the paracentral macula, there was a significant increase in thickness in all sectors, except the inferior sector. This significant changes were also found in the superior and temporal sectors of the peripheral macula.

Another study by Subramaniam [15], has divided the subjects into 2 different groups: group I who removed the cataract by ECCE and group II who removed the cataract by phacoemulsification, he found that the incidence of clinical CME was $1.5 \%$ in ECCE (group I) while it was $2 \%$ in the phacoemulsification (group II). In contrast Mentes [16], has found that the CME was not detected in any eye at any postoperative follow up periods. The incidences of the clinical CME after the uncomplicated phacoemulsification sergury was $0 \%$.

According to Dvali [17] the RNFL thickness increased after cataract surgery due to the improvement RNFL reflectivity after the removal of the opacified media, the incidence of clinical CME has been reported to be $0 \%-6 \%$ after phacoemulsification due to many factors which affect the tissue structures of the eye as the surgical trauma to the iris, ciliary body and lens epithelial cells which causes the release of prostaglandins and other inflammatory mediators. These inflammatory mediators diffuse through the vitreous and disrupt the blood retinal barrier and causes the macular edema [17].

\section{Conclusion}

This study supported the concept that the retina is affected by phacoemulsification as the ultrasonic energy produce a mechanical effects that cause an inflammatory reaction which release phospholipids and prostaglandins and other inflammatory mediators. The inflammatory mediators diffuse through the vitreous and disrupt the blood retinal barrier to cause macular edema which is the most common cause of visual impairment after phacoemulsificastion. The increase of RNFL thickness occur because the media opacity increases the light scattering and absorption, so the RNFL thickness measurement can be increased after the uncomplicated cataract surgery. The high resolution SD-OCT technology perrmitts the masurement of different retinal layer thickness accurately so, this allowes better assessment of the retinal nerve fiber layer and macula thickness. As proved by this study; hacoemulsification can cause a significant increase in the RNFL and central macular layer thickness in the 1 st week \& the 1 st month after the surgery than before it.

\subsection{Sources of funding}

This research did not receive any specific grant from funding agencies in the public, commercial, or not-for-profit sectors. 


\subsection{Conflicts of interest}

No conflicts of interest

\section{References}

[1] B. Sharma, RG .Abell, T .Arora, T .Antony, RB .Vajpayee, Techniques of anterior capsulotomy in cataract surgery. Indian $\mathbf{J}$ Ophthalmol, Vol.67(4), pp.450,2019.

[2] JH. Park, SM .Lee, JW .Kwon, MK. Kim, JY .Hyon, WR .Wee, Ultrasound energy in phacoemulsification: a comparative analysis of phaco-chop and stop-and-chop techniques according to the degree of nuclear density. Ophthalmic Surgery, Lasers Imaging Retin., Vol.41(2), pp.23641,2010.

[3] M .Rękas, R .Montés-Micó, K .Krix-Jachym, A. Kluś, A. Stankiewicz, T .Ferrer-Blasco, Comparison of torsional and longitudinal modes using phacoemulsification parameters. J Cataract Refract Surg, Vol.35(10), pp.1719-24,2009.

[4] RH .Masland, The neuronal organization of the retina. Neuron., Vol.76(2), pp.26680,2012 .

[5] TD. Lamb, Why rods and cones? Eye, Vol.30(2), pp.179,2016

[6] S. Walia, GA .Fishman, DP. Edward, M. Lindeman, Retinal nerve fiber layer defects in RP patients. Invest Ophthalmol Vis Sci., Vol.48(10), pp.4748-52,2007.

[7] RJ .Antcliff, J .Marshall, The pathogenesis of edema in diabetic maculopathy. In: Seminars in ophthalmology. Taylor \& Francis, Vol. 45(8), pp. 223-32,1999.

[8] K. Miyake, N. Ibaraki, Prostaglandins and cystoid macular edema. Surv Ophthalmol, Vol.47, pp.S203-18,2002.

[9] A .Koustenis, A .Harris, J .Gross, I .Januleviciene, A .Shah, B. Siesky, Optical coherence tomography angiography: an overview of the technology and an assessment of applications for clinical research. Br J Ophthalmol, Vol.101(1), pp.16-20,2017.

[10] M .El-Ashry, S .Appaswamy, S .Deokule,
S. Pagliarini, The effect of phacoemulsification cataract surgery on the measurement of retinal nerve fiber layer thickness using optical coherence tomography. Curr Eye Res, Vol.31(5), pp.409-13,2006.

[11] CSM .Cheng, MG .Natividad, A .Earnest, V .Yong, BA .Lim, HT. Wong, Comparison of the influence of cataract and pupil size on retinal nerve fibre layer thickness measurements with time-domain and spectral-domain optical coherence tomography. Clin Experiment Ophthalmol, Vol.39(3), pp.215-21,2011.

[12] I .Perente, CA. Utine, C .Ozturker, M .Cakir, V .Kaya, H. Eren, Evaluation of macular changes after uncomplicated phacoemulsification surgery by optical coherence tomography. Curr Eye Res, Vol.32(3), pp.241-7,2007.

[13] AT. Yazici, E .Bozkurt, ÇD. Altan, S .Albayrak, M .Çakir, N. Alagoz, Macular thickness changes after phacoemulsification combined with primary posterior curvilinear capsulorhexis. Eur J Ophthalmol, Vol.20(2), pp.376-80,2010.

[14] G .Pardianto, N .Moeloek, J .Reveny, S .Wage, I .Satari, R. Sembiring, Retinal thickness changes after phacoemulsification. Clin Ophthalmol (Auckland, NZ), Vol.7, pp.2207,2013.

[15] ML. Subramanian, AK. Devaiah, KA .Warren, Incidence of postoperative cystoid macular edema by a single surgeon. Digit $\mathbf{J}$ Ophthalmol DJO, Vol.15(4), pp.37,2009.

[16] J. Mentes, T .Erakgun, F .Afrashi, G .Kerci, Incidence of cystoid macular edema after uncomplicated phacoemulsification. Ophthalmologica, Vol.217(6), pp.40812,2003 .

[17] M. Dvali, O .Tsertsvadze, S .Skhirtladze, incidence of cme after hydrophilic and acrylic iol implantation-oct results. Georgian Med News, Vol.(291), pp.425,2019 . 